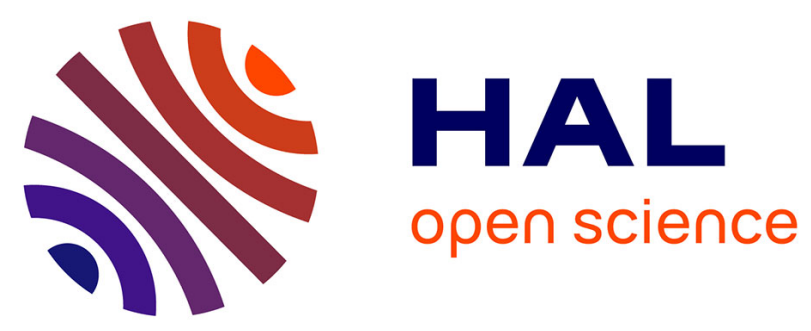

\title{
Possible ice-wedge polygonisation in Utopia Planitia, Mars and its poleward gradient of latitude
}

Meven Philippe, Richard J Soare, Susan Conway, Jean-Pierre Williams, Lauren E Mc Keown, Etienne Godin, Jordan Hawkswell

\section{To cite this version:}

Meven Philippe, Richard J Soare, Susan Conway, Jean-Pierre Williams, Lauren E Mc Keown, et al.. Possible ice-wedge polygonisation in Utopia Planitia, Mars and its poleward gradient of latitude. Europlanet Science Congress, Sep 2020, Virtual meeting, France. 10.5194/epsc2020-385 . hal-02989934

\section{HAL Id: hal-02989934 \\ https://hal.science/hal-02989934}

Submitted on 5 Nov 2020

HAL is a multi-disciplinary open access archive for the deposit and dissemination of scientific research documents, whether they are published or not. The documents may come from teaching and research institutions in France or abroad, or from public or private research centers.
L'archive ouverte pluridisciplinaire HAL, est destinée au dépôt et à la diffusion de documents scientifiques de niveau recherche, publiés ou non, émanant des établissements d'enseignement et de recherche français ou étrangers, des laboratoires publics ou privés. 


\section{Possible ice-wedge polygonisation in Utopia Planitia, Mars and its poleward gradient of latitude}

Richard J. Soare ${ }^{1}$, Meven Philippe ${ }^{2}$, Susan J. Conway ${ }^{2}$, Jean-Pierre Williams ${ }^{3}$, Lauren E. Mc Keown ${ }^{4}$, Etienne Godin ${ }^{5}$, and Jordan Hawkswell ${ }^{6}$

${ }^{1}$ Geography Department, Dawson College, Montreal, Qc, Canada

${ }^{2}$ Laboratoire de Planétologie et Géodynamique, UMR, CNRS 6112, 2 rue de la Houssinière, 44322, Nantes, Cedex 3, France

${ }^{3}$ Earth, Planetary and Space Sciences, University of California, Los Angeles, CA, USA

${ }^{4}$ School of Natural Sciences, Trinity College Dublin, Ireland, Dublin 4, Ireland

${ }^{5}$ Centre for Northern Studies, Laval University, Quebec City, Qc, Canada

${ }^{6}$ Ocean Wise, PO Box 3232, Vancouver, BC, Canada

\section{Introduction}

On Mars, polygonally patterned ground is widespread at the mid to high latitudes and it is accepted to result from thermal contraction of ice-cemented soil ${ }^{1}$. Low-centered polygons (LCPs), i.e. polygons with a relatively lower elevation at their centre (Figure 1a), and high-centered polygons (HCPs), i.e. polygons with a relatively higher elevation at their centre (Figure 1b), can be observed at the martian mid latitudes ${ }^{2}$.

On Earth, ice-wedge polygons are morphologies that are formed when ice aggrades on a seasonal basis in thermal contraction cracks in ice-cemented soil ${ }^{3}$. This aggradation uplifts the sediment at the polygon margins forming LCPs. When ice-wedge polygons degrade as mean seasonal temperatures rise, the melting of the ice in the wedges drops the elevation at the polygon margins, forming $\mathrm{HCPs}^{3}$.

Both LCPs and HCPs can also be formed when the wedge-material is wind-blown sand, rather than ice; however, were the wedges comprised of sand a variance in morphology based on a change of latitude would not be expected since in this case the type of polygon expressed should not depend on the ambient thermal conditions. Therefore, based on the assumption that ground ice stability increases poleward on Mars ${ }^{4}$, we hypothesise that the relative abundance of LCPs compared to HCPs should increase with latitude if these polygons are a result of ice wedges rather than sand wedges. We test this hypothesis in a region of Utopia Planitia (Figure 2), where there is good coverage of high-resolution images sufficient to distinguish LCPs from HCPs and the widespread occurrence of polygonally patterned ground ${ }^{5}$.

\section{Method}

We used 73 High Resolution Imaging Science Experiment (HiRISE) images at 25-50 cm/px over the Utopia Planitia study region (Figure 2). 59 images remain to be analysed for a total of 132 . The 
study area was divided into squares of $250,000 \mathrm{~km}^{2}$, and for each one the presence or absence of LCPs and HCPs in the images was noted - where there were overlapping images only the highest quality image was assessed. At least five LCP- or HCP-type polygons must occur per square for their presence to be noted. Images were divided into two groups: the ones whose resolution/quality allows unambiguous identification of LCPs and/or HCPs when present (47 images, 29 with polygons), and the ones where identification was more challenging (26 images, 20 with polygons) e.g. because of low resolution, small polygon sizes, poor contrast, and/or atmospheric haze. Three further images were of insufficient quality for analysis. We distinguished two types of host terrain: "craters" $(\geq 2$ $\mathrm{km}$ diameter) and inter-crater plains. Finally, the ratio of the number of LCPs to the number of HCPs was calculated for each degree of latitude for both terrain types, and also for each image.

\section{Results}

We compared the data from the low resolution/quality images to the higher resolution/quality images and found the same latitudinal trends in the LCP-to-HCP ratio. We therefore considered these images as having reliable data, and results from both groups are reported in the subsequent analysis. In Figure 2 we show the LCP-to-HCP ratio per HiRISE image, however below and in Figure 3 we report the LCP-to-HCP ratio calculated for every $1^{\circ}$ of latitude no matter which image they fall within.

If the LCP-to-HCP ratio is plotted for the polygons in craters and on the plains separately, polygons located on the inter-crater plains show a strong correlation between latitude and LCP-to-HCP ratio $\left(\mathrm{R}^{2} \approx 0.86, \mathrm{p}\right.$-value $\approx 0.0003$; Figure 3$)$. Note that the LCP-to-HCP ratio is nearly always higher in craters than it is on the plains particularly at lower latitudes. However, no latitudinal trends are observable in the LCP-to-HCP ratio for polygons in craters $\left(R^{2} \approx 0.12\right.$; Figure 3$)$. Note that the extreme value of 6 in the LCP-to-HCP ratio at $40^{\circ} \mathrm{N}$ originates from two $30-40 \mathrm{~km}$ craters in which LCPs are very common and at this latitude no other HiRISE image with polygons has been found. When the data are analysed as an ensemble (i.e. the host terrain type is not taken into account), we find no correlation between latitude and LCP-to-HCP ratio $\left(R^{2} \approx 0.28\right)$.

\section{Conclusions}

- polygons located on the plains in Utopia Planitia show a positive correlation between latitude and LCP-to-HCP ratio that is statistically strong. This provides evidence in support of the hypothesis that these polygons have ice-wedges at their margins whose degradation increases towards the equator ${ }^{1}$.

- the LCP-to-HCP ratio of polygons inside craters does not show any trend with latitude. We suggest that the micro-environment inside the crater could protect the ice-wedges from degradation: craters could form cold traps where volatiles are preferentially preserved ${ }^{6}$. This is supported by the higher LCP-to-HCP ratio in craters compared to the plains and the occurrence of polygons in craters to lower latitudes than on the surrounding plains. Our next step will be to examine the other factors that could influence the type of polygon that occurs inside craters, including elevation, crater diameter and preservation state. 


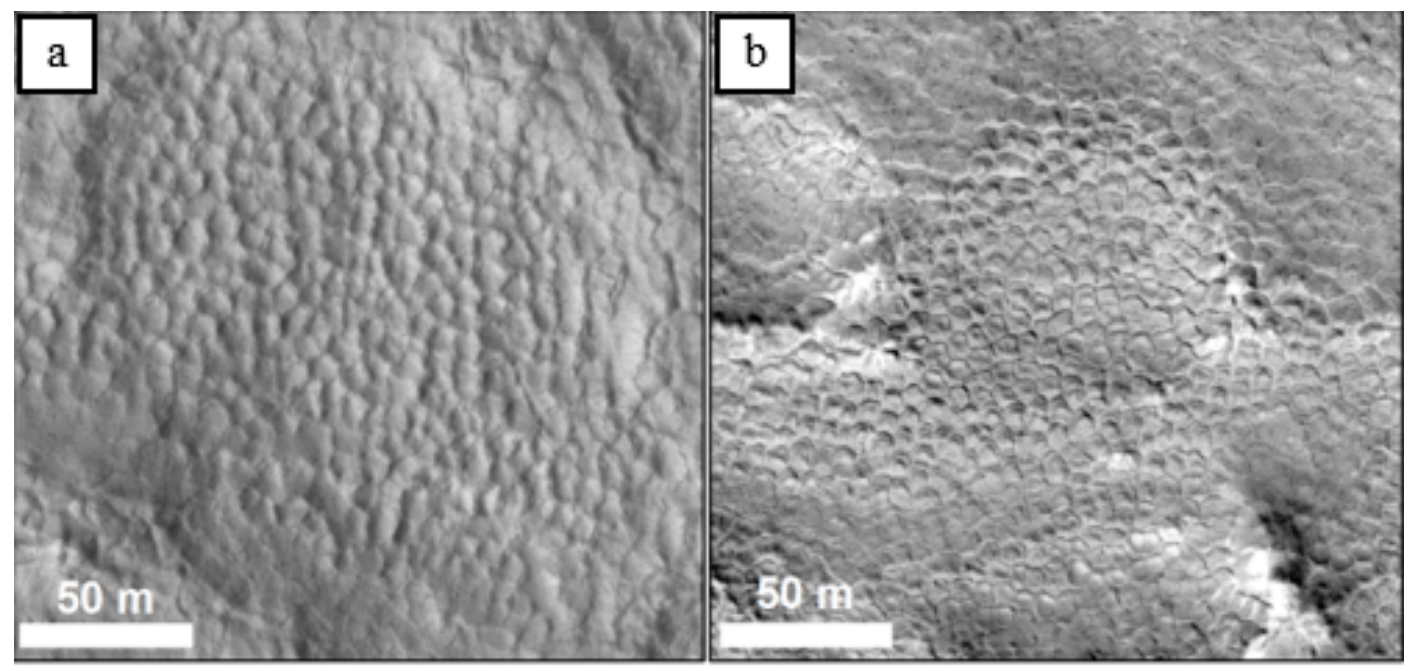

Figure 1: low-centered (a) and high-centered polygons (b) in Utopia Planitia, Mars. Sunlight is coming from the left.

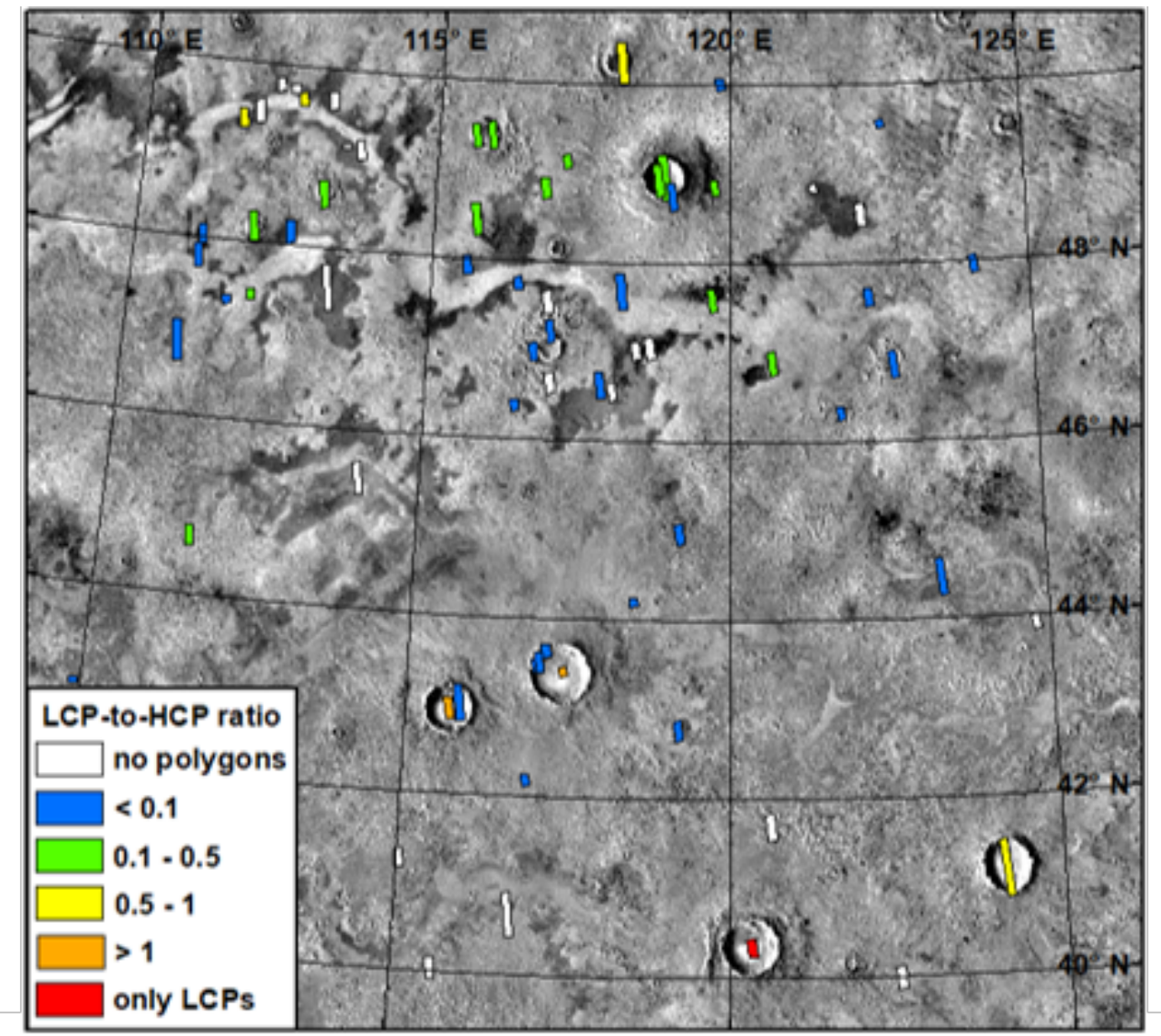

Figure 2: view of Utopia Planitia, Mars in Lambert conformal conic projection. The footprints of HiRISE images that have been scanned so far are displayed with different colours according to their ratio $\mathrm{LCP} / \mathrm{HCP}$, from blue (ratio $<0.1)$ to red (ratio $>1)$. 


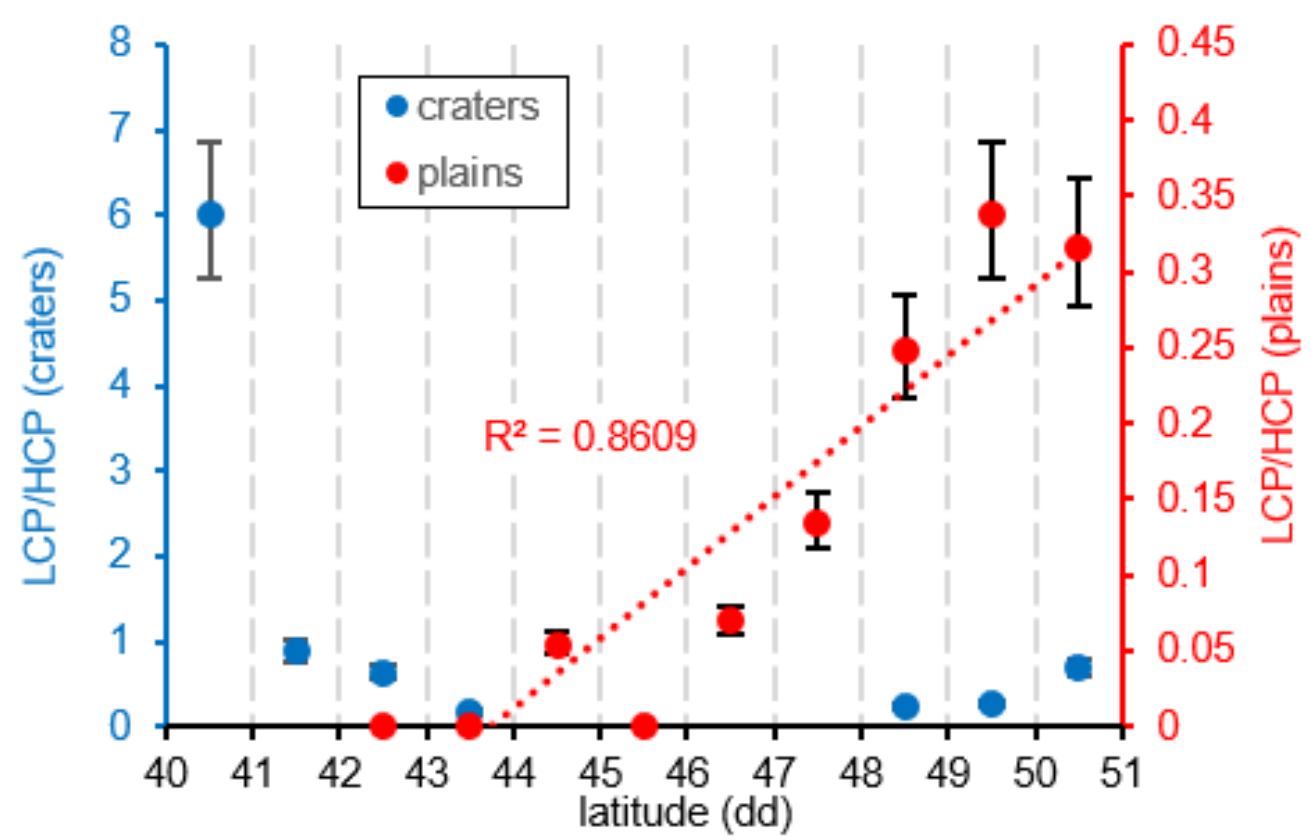

Figure 3: latitudinal variation of the LCP-to-HCP ratio for both plains (red points) and crater terrains (blue points). Data have been binned for each $1^{\circ}$ of latitude. The red dotted line represents the linear correlation between $\mathrm{LCP} / \mathrm{HCP}$ and latitude for plains, its $\mathrm{R}^{2}$ value specified above. Error bars are calculated from an estimated error of mapping of $1 / 15$ squares, and are not visible if falling within the points.

\section{References}

${ }^{1}$ Mellon M.T. (1997) J. Geophys. Res. 102 (E11), 25,617-25,628.

${ }^{2}$ Soare R.J. et al. (2018) Chapter 7, in, Dynamic Mars, recent landscape evolution of the red planet, eds. Soare, R.J., Conway, S.J. and Clifford, S.M., Elsevier, 464 p.

${ }^{3}$ Lachenbruch A.H. (1962) GSA Special Paper 70. vol. 69 Geological Society of America, New York.

${ }^{4}$ Schorghofer N., Forget, F. (2012) Icarus 220, 1112-1120.

${ }^{5}$ Soare R.J. et al. (2020) Icarus 342, 113233.

${ }^{6}$ Conway S.J. et al. (2012) Icarus 220, 174-193. 